\section{Ant Adurrem} on

\section{SOME POINTS IN CONNEXION WITH RENAL DISEASE.}

Delivered Before the Lambeth DIvision of the British Medical Association.

BY

CHARLES R. BOX, M.D.Lond., F.R.C.P., F.R.C.S., PHYSICIAN TO ST. THOMAS's FOSPITAL AND TO TIIE LONDON FEVER HOSPI'AL.

Some of the recent investigations on nepluritis are of practical importance, and I havo been fortunate in having the opportunity of proving their value both in treatinent and prognosis. The opportunity arose from the fact that Dr. Hugh MacLean and Dr. De Wesselow have been and are still engaged at St. Thomas's Hospital in an investigation on war nephritis. With the greatest readiness they have collaborated in the investigation of my ward cases and placed their knowledge at my disposal. Before going further I hasten to express my indebtedness to their published results and to them personally for many facts gleaned during conversations with them.

It is well known that the predominant symptoms of renal disease fall into two main groups-the oedematous and the cardio-vascular. In acute nephritis both sets of symptoms may bo present, although not always in equal degree; in chronic nephritis the predominance of symptioms of one or other of these groups enables us to recognize two distinct types-the chronic parenchymatous or tubal and the chronic interstitial or granular form.

Nephritis of the chronic parenchymatous type is characterized by profuse albuminuria and diminution of the quantity of urine passed, coupled with obtrusive oedema and effusions into the serous sacs, but cardio-vascular changes are not at all a pronounced feature. The chronic interstitial form, on the other hand, is distinguished by scanty albumin, increased excretion of urine of low specific gravity, cardiac hypertrophy, and raised arterial tension. Oedema is not present in this type until the terminal stages, and then is not of the renal distribution but of that variety which is attributed to cardiac failure.

Whether these two forms of chronic nephritis originate as such or develop from the continued selective action of an antecedent attack of acute inflammation we will not now linger to discuss. I propose rather to direct your attention to some interesting facts which have a bearing on the symptomatology and treatment of the two types. For many years we had to be content with the results of urinary analysis alone when investigating cases of renal disease. Estimation of the quantity of albumin, the detection of blood, measurement of the amount of water passed, determination of the specific gravity, and, it may be, an estimation of the urea and chlorides, were the points to which, in conjunction with a microscopical examination of the sediment, attention was chiefly directed, and there is no doubt that in this way most instructive information may be obtained.

But a much clearer insight into what is happening may be gained by a combination of urinary analysis with periodical examinations of the blood. Improved methods now enable the clinical pathologist to estimate with accuracy the urea content, the chloride content, and the amount of protein in a small sample of the blood, and so to throw a flood of light on some of the problems of renal disease. The methods are laboratory procedures, and it is not my province to describe them, but they have important clinical bearings, and it is important that we slsould be acquainted with the inain facts which have come to light, and see low they fit in with our clinical knowledge.

\section{The Percentage of Urea in the Urine and in} The Blood in Nephritss.

In the early stage of acute nephritis all the functions of the kidney suffer, among them the power of excreting urea, so that there is generally a marked defect in the elimination of this body, together with a diminution of the amount of urine passed. In favourable cases this retention is transitory, and normal climination is sooner or later re-established.
In chronic nephritis, however, observations on the urea excretion have led to discordant results. Attempts to correlate the urea excretion of chronic nephritic patients with their clinical condition net with no success. Tho reason of this failure gradually became obvious. The renal mechanism is such that under circumstances of stress the kidneys are capable, even though much damaged, of eliminating a quantity of urea which is approximately normal, but they do so-and this is the important pointby secreting an additional quantity of water. We must therefore, in attempting to gauge the renal efficiency, take into consideration both factors; in other words, the per. centage of urea in the urine or the urea concentration is our criterion, and not merely the amount of urea excreted in the twenty-four hours.

The urine of a normal individual on ordinary diet con. tains about 2 per cent. of urea. For patients under observation in hospital an average of 1.6 per cent. is found to be nearer the mark if the kidneys are healthy. When the kidneys are damaged the concentration falis below this figure.

That the specific gravity of the urine is consistently low in cases of advanced granular kidney is a well recognized fact, and these are precisely the cases in which difficulty of urea excretion is particularly marked. It may be asked, therefore, Why not take the specific gravity of the urine as a criterion of renal efficiency in place of tine more troublesome urea estimation? Although the determination of the specific gravity of one sample miglit not be reliable, the average over a week or longer might yield useful information. An objection to this method lies in the fact that the clilorides and sulphates form hoavier solutions than does urea, so if these salts are deficient the specific gravity will fall, and also the specific gravity will be low if excessive fluid is being ingested and excreted, quite apart from urea defect. None the less there is a marked tendency for a low specific gravity to accompany low urea concentration, and it is difficult for an extremely granular kidney to secrete urine of a greater specific gravity than 1012 at the highest. I have several times found this test valuable in making the distinction betweon the granular kidney and the kidney of arterio-sclerotic heart failure.

The late Dr. Foxwell of Birmingham paid especial attention to the subject of urea excretion in conjunction with the amount of urine passed, and he concluded that an increase in quantity to $60 \mathrm{oz}$. per diem or more was indicative of renal fibrosis, just as was a specific gravity below 1012. Combining the specific gravity, the quantity of urine passed, and the percentage of urca, his analyses led him to the following formulae:

\begin{tabular}{|c|c|c|c|c|c|}
\hline & & $\begin{array}{l}\text { Specific } \\
\text { Gravity. }\end{array}$ & Quantily. & $\begin{array}{c}\text { Urea } \\
\text { Percent- } \\
\text { age. }\end{array}$ & $\begin{array}{l}\text { Total } \\
\text { Urea. }\end{array}$ \\
\hline Healthy male $\ldots$ & $\cdots$ & 1019 & $\underset{39}{\text { Ounces. }}$ & 2.1 & Grains. \\
\hline Ifealthy female ... & $\cdots$ & 1019 & 28 & 1.8 & - \\
\hline Moderate work possiblo & ... & 1012 & 50 & 1.4 & 310 \\
\hline Occasional light work & & 1011 & 45 & 1.3 & 238 \\
\hline Confined to bed... & .. & 1010 & 40 & 1.0 & 175 \\
\hline
\end{tabular}

Although a patient suffering from chronic nephritis may, with the aid of polyuria, excrete as much urea in the twenty-four hours as does a patient with normal kidneys, examination of the blood brings to light a marked dif ference in the two cases. Tho normal individual on o: dinary diet will have in his blood a urea content of 20 to $40 \mathrm{mg}$. per 100 c.cm., whereas in that form of chronic renal disease which leads to the retention of non-protein nitrogenous bodies, of which urea is the chief and is talren as the index, the urea content of the blood may rise to $100 \mathrm{mg}$. per $1(\mathrm{~S}$ c.cm. or higher. A similar retention may occur in acute nephritis also, and in some cases of renal disease the percentage has been found to rise to 300 or even $600 \mathrm{mg}$. It appears that any rise above $300 \mathrm{mg}$. is of fatal prognostic import.

In all forms of acute nephritis urea retention is a very constant feature, but in chronic nephritis it is only chameteristic of cirrliotic, granular, or fibrosed kidneys, as opposcd to the chronic parenchymatous or chronic tubal varioty of
the disease. 
On the facts which they have ascertained with regard to urea retention and urea excretion 'Maclean and De Wesselow have based a new and simple tert which promises to be of much practical value in mephritis. Fifteen grams of urea are dissolved in 100 c.cm: of water. This draught, which may be flavoured with tincture of orange, is administered the first thing in the morning on an empty stomach, the urinary bladder at the same time being emptied. Two hours later the bladder is again emptied, and the concentration of urea in the specimen is determined. With normal kidneys the concentration will be from 2 to 3.5 per cent. With a concentration of 1.5 per cent. the kidney is only moderately efficient, whilst a concentration of 1 per cent. or less indicates that the kidneys are severely damaged. Low concentration- is generally correlated with urea retention in the blood. There is one fallacy which must be guarded against-urea may cause coneiderable diuresis in some normal individuals. So, if the specimen obtained two hours after administration shows a low concentration, a further specimen should be obtained an hour later, by which time diuresis should have ceased. If the concentration is still low the kidney is not normal.

It may be mentioned that in cases in which urea retention occurs this substance is also found in excess in the cerebro-spinal fluid. The normal content of this fluid ganged. by the hypobromite method is said to be 0.006 per cent.; whilst in renal impermeability to urea it may rise to 0.1 per cent., and in some instances is as high as 0.6 per cent. In this fluid concentrations above 0.3 per cont. are said to indicate a fatal issue.

From what lras been said it is evident that a knowledge of the amount of urea present in the blood, and incidentally also in the cerebro-spinal fluid, affords two importan indications: In the first place, it tells us that a certain type of renal inadequacy is present, and in the second, it affords prognostic indications which, in a certain number of cases, cannot be arrived at by other means.

That urea itself produces toxic symptoms it is not possible to assert. The general opinion hitherto has been that urea itself is a comparatively harmless substance. We must not forget that nrea retention goes hand in hand witl the retention of other non-protein nitrogenous bodies such as uric acid, creatinin and purin bases; and.we. must also remember that those renal cases which have ures retention are sooner or later characterized by raised arterial pressure and cardiac hypertrophy. Some interesting considerations bearing on the absence of renal dropsy in cases of this type will be mentioned presently. That uraemic con. valsions. may occur when urea retention is present the following case well shows; but Dr. Mackean tells me that his investigations have led him to the conclusion that it is not possible to predict uraemic convulsions from th amount of urea found in the blood. Indeed, the chronic cases with the highest amount of urea retention are more likely to be characterized by uraemic twitching and coma than by explosive convalsion.

J. G., a delicate-looking lad of 12 years, was admitted under me in December, 1919, with oedema of face and ankles; and history of two days' obvious haematuria. Five years ago h was laid up with pneamonia, and ho wont through a sharp attak of ante roun a shar illness. A fortnight before admission he complained of sore throat, but had no pyrexia, rash, or other complained of sore On examination he was found to be pale, with moderate On examination he was found to be pale, with moderate
oedema of the face and ankles. There was evidence of a little oedema of the face and ankles. There was evidence of a little
fluid at the bases of the pleural sacs, and the heart was slightly enlarged. The blood pressure was $120 \mathrm{~mm}$. The urine wa diminished in quantity, an average of $30 \mathrm{oz}$. being passed in th twenty-four hours. Much albumin was present, also blood. The sediment contained epithelial, blood and hyaline casts in some quantity. The blood urea was $140 \mathrm{mg}$. per cubic centimetre, and the urine contained only the smallest trace of chloride, so both urea retention and chloride retest trace of marked. The temperature was slightly febrile; the tonsils warke chronically enlarged.

Six days after admission he had, without warning, a series of severe convulsive fits followed by a state of semi-coma. Venesection to the amount of one pint followed by satine. infusion of $30 \mathrm{oz}$. caused immediate improvement, and the fits did not recur. Profuse sweating was induced by hot packs, and nothin but milk and barley water allowed. Four days later the blood urea was found to have fallen to $54 \mathrm{mg}$. and the blood pressure to $112 \mathrm{~mm}$. A week later still the blood urea was $35 \mathrm{mg}$. Coincident with this fall, and no.doubt responsible for it, was an increasing polyuria rising to 70 or $80 \mathrm{oz}$. per diem. At the same time the albumin in the urine, which at first amounted to 7 grams per litre, had fallen to $\frac{1}{2}$ gram. the fall being gradual. He is still under observation.

C
Salt Retention and its Results.

It has long been known that retention of chlorides in the body can produce oedema of the tissues and serous effusions, water being retained to keep the salt concentra. tion in the tissues down to the normal limit of 0.6 per cent. sodium chloride solution. In other words, for every 6 grams of salt retained, the body will store up $1,000 \mathrm{c.cm}$. of water. A very important function of the. kidney is the regulation of the concentration of salt in the plasma. In certain forms of nephritis the kidney appears to lose the power of excreting chloride in the normal manner; these forms of nephritis are those which are associated witl oedema; they may be acute or chronic in character, but their essential characteristic is that they are paren. chymatous or tubal in type.

Blood examination does not throw much light on chloride netention, because diminished chloride excretion dues not produce an increased concentration of the salt in the blood and tissues owing to the simultaneous and inseparable retention of water, which acts as a diluent.

It may be mentioned in passing that a primary retention of water would also lead to a compensatory retention of salt, and it is believed that under certain circumstances this may occur, although, generally speaking, it may be said that in oedema water is retained to dilute the salt and not salt to salinate the water.

A normal kidney excretes the day's intake of salt (15 to 20 grams) within the next twenty-four hours, and in the non-oedematous forms of renal disease-that is, the granular kidney-salt is excreted equally well, the capability of excreting salt being quite independent of the power of excreting many other substances, such as urea, uric acid, and potassium iodide. The power of excreting phosphates and sulphates is, unlike that of excreting chlorides, roughly parallel with the capability of excreting urea. Salt retention is a characteristic of the oedematous or tubal type of nephritis, just as urea retention is characteristic of the chronic interstitial or cirrhotic type.

The accurate determination of salt retention is not such a simple matter as the estimation of urea retention. The amount of salt which will be excreted after a weighed dose of sodium chloride depends a great deal on the amount of fluid present in the tissues of the body at the time of administration. If the body is low in fluids, the salt may actually be retained, the body fluids correspondingly augmented, and the weight raised. So, for the estimation of salt retention, an equilibrium must first be established between intake and output by careful dieting, and then large doses of salt mast be repeated on successive days. If salt is retained, an increase in weight at once takes place, owing to the retention of fluid; but in a healthy individual this increase is limited to a few days; it then ceases, and there is excreted in the urine a quantity of salt equivalent to that taken by the mouth. On the other hand, if salt retention is present, dropsy should ensue, and perhaps also serous effusions. The test obviously is a difficult one to apply, so for ordinary purposes reliance is placed simply on the estimation of the chlorides in the urine.

The following case, although not one of nephritis, is a striking example of the results of flooding the tissues with an excess of salt:

On November 4th, 1916, a girl aged $2 \frac{1}{2}$ years was brought to St. Thomas's Hospital on account of oedema of the feet and face. Her only previous illnesses were whooping-congh and chicken-pox.

For three weeks she had shown slight nasal catarrh ; recently her face had been swollen in the mornings, and latterly ber feet had become swollen slso.

Physical examination revealed nothing to account for the oedema. The urine was free from albumin, its specific gravity was 1020 ; it was concentrated and full of urates. No sugar. As

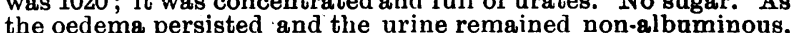
she was admitted for further observation. But meantime an she was admitted for further observation. But meantime an important fact had come to light-it had been ascertained that tunity offered, empty the salt cellar as if it were a sugar basin.

On admission the temperature was $100^{\circ}$, but fell to normal before night. Slight bronchitis with some respiratory acceleration was present. The urine was still concentrated, but free from albumin. The child was placed on milk diet.

In a day or two sharp crepitation made its appearance in the lungs and gradually extended in area and intensity. The tem. perature became febrile. There was still no albumin, and the perature became febrile. There was still no albumin, and the
quantity of urine averaged 6 or $7 \mathrm{oz}$. a day-that is, at least a third, or possibly a fourth, of what it should have been.

The pulse and respiration rates gradually increased, the 
former reaching 172 and the latter 96. Death of the asphyxial type occurred after she had been under observation for eight days.

\section{Post-mortem Examination.}

The legs were swollen and oedematous. There were severa adhesions between the chest walls and lungs on both sides, evidently of old standing. With the exception of the lungs the thoracic and abdominal organs showed no gross signs of dis ease The lungo were suborepitant, and pitted all over with smail cavities, on the average not much larger than the head of a pin.

I am indebted to Professor S. G. Shattock for the following histological report:

Kianey.-There are no marks of glomerular inflammation. The capillary endothelium is normal, and there is no exudate within the capsules. In all the convoluted tubules the epithelium is remarkably and coarsely vacuolated, but without destruction of the cell nuclei. The lumina of the tubules are in many cases obliterated by a coarse open spongework formed by the septa of the vacuolated parts of the cells. In some cases the whole of the cell is vacuolated, but as a rule the basal moiety. containing the nucleus is affected to a lesser degree or not at all. There is nowhere any coagulated exudate within the tubules. Nor is there any vascular congestion. The the tubules. Nor siewed as one of inflammation, but represents one of dropsical vacuolation of inflammation,

he epithelium

Lung.-The pulmonary alveoli and the infundibula, as well as certain of the bronchioles, are filled with cells. These cells within the alveoli and infundibula consist partly of proliferated epithelium but largely of polymorphonuclear leucocytes. There is no coagulum entangling the cells of the kind me with in a croupous inflammation. The condition may be classed as one of bronchopneumonia. Distributed through the classed as one of bro there are a conspicuous number of sharply solidified substance there are a conspicuous number of sharply defined spaces of circular, polygonal or elongated form which represent dilated infundibula and dilated bronchioles. With
few exceptions the epithelium lining the spaces has been lost by desquamation. There is no necrosis in progress, and the condition may be regarded as one of infundibulobronchiolectasis.

The lesson to be learned from such cases as this is that excess of salt will produce subcutaneous oedema, and also oedema of the cells and framework of parenchymatous organs. Cases of a somewhat similar character have at times been reported by other observers. Also it is well known that heavy saline infusions can induce hydrothorax, hydroperitoneum, oedema of the lungs, and sometimes, too, of the subcutaneous tissues.

There being no doubt about the presence of salt retention in certain types of nephritis with oedema, the tendency to look upon this retention as the cause of the dropsica manifestations is natural. This is the view strongly taken by Widal and his school, a view which has supplanted the older idea that oedema is due to the inability of the kidneys to secrete sufficient water. A third hypothesis must be mentioned - that of Cohnheim-which attributes the oedema to an increased permeability of the walls of the capillary vessels, induced by malnutrition or by the retention of toxic products. But Cohnheim's view has not survived the test of experiment; this increased capillary permeability luas been proved not to exist.

Widal's salt retention hypothesis is attractive, and there is no doubt that under certain circumstances a salt-free diet is beneficial in the treatment of dropsy and oedema, whilst administration of excess of salt will aggravate the condition. Clinically, however, this line of treatment has not led to the results which might have been expected. Moreover, in some conditions in which analysis of the urine indicates that salt retention is present, dropsy and oedema fail to appear; it is possible, however, that in such cases salt is being vicariously eliminated by the bowel.

There is strong reason to believe that something more than mere salt retention lies at the root of renal dropsy.

The Treatment of Chronic Renal Dropsy.

Chronic parenchymatous nephritis-the large white kidney-affords the most striking example of oedema and serous effusions associated with renal disease. Sufferers from this disease become absolutely waterlogged, and there is no doubt that in many cases this oedema is an important factor in producing death, which is said, as a rule, to occur within two years or less of the recognition of the disease. Not only are mechanical disabilities produced by the effusions, but the waterlogged organs, subcutaneous tissues, and serous sacs also fall an easy prey to secondary inflammatory complications.

The dropsical effusions can, of course, be removed by' mechanical means-that is, by puncture of the skin and subcutaneous tissues, by tapping the abdomen, und by aspirating the chest-but these procedures are merely palliative; they have to be repeated periodically, and, in addition to the discomfort inflicted, they carry a very real risk of septic infection. Attempts to reduce the dropsy by means of diuretics, diaphoretics, and purgatives are notoriously ineffectual, and the use of a salt-free diet, as above mentioned, has not led to the results expected.

There is, however, a means by which the effusions and oedema can be got rid of. This method we owe to Dr. Albert Epstein of New York, who, in an article published in the American Journal of Medical Sciences in November, 1917, urged the efficacy for this purpose of a dietary rich in proteins but poor in fats. Deferring for the present a consideration of the facts which led him to adopt this revolutionary method of dieting in nephritis, and also of its possible sequel, let me first give the details of an illustrative case

A. H., a porter 36 years of age, was under my care in $\mathrm{St}$ Thomas's Hospital from February 1st, 1918, until March 3rd 1919-a period of fourteen months-and is still under observa tion as an out-patient. He is a married man with two healthy children. His only previous illness was an attack of rheumatio fever fourteen years ago. There is no history of renal disease in his family. His four brothers and sisters are healthy and his parents are said to have died "natural deaths." Despite careful inquiries no cause for nephritis could be traced. There was nothing in his occupation which had any bearing on it his habits were apparently above reproach; no :history of venereal disease was obtained, and the Wassermann reaction was negative. The mouth contained five septic stumps, which were at once removed.

The first sign of his illness was slight oedema of the feet and puffiness of the eyelids, noticed seven weeks before he was admitted to hospital. The dropsy steadily increased. He began to suffer from frontal headaches and developed a rather troublesome cough. He noticed that he passed but little urine

When admitted, both legs were much swollen and pitted readily. A large cushion of oedema occupied the lumbar region. The abdomen was full of fluid and the face puffy. There were no obvious cardio-vascular changes and no retiniti or oedema of the optic discs. The blood pressure was $145 \mathrm{~mm}$ The chest was moderately emphysematous and the lung base showed signs of oedema. There was a small quantity of slightly blood-stained muco-purulent sputum, which, however, was freo from tubercle bacilli. Both pulse and respirations were slightly accelerated. The temperature was normal. The urine was acid and clear; its specific gravity varied from 1015 to 1025 ; and the daily quantity averaged a little over 30 ounces; there was a the daily quantity averaged a little over 30 ounces ; there was a
dense cloud of albumin on boiling but no blood; a few granular and epithelial casts were found

The ascites increased, and slight pleural effusions appeared on both sides. The penis, and scrotum became highly oedematous, and at the same time the oedema of the legs, which at first was below the knees, invaded the thighs, the patient becoming completely waterlogged. The only uraemio symptoms consisted in the headache already mentioned and an occasional tendency to vomit.

For the first month his diet consisted of three pints of milk, a certain amount of carbohydrate, and occsionsily fish milate some fowl was added. In succession, pituitary extract, caffeine citrate, diuretin, and a mixture of potassium nitrate, spirits of nitrous ether, and ammonium acetate were administered as diuretics without the slighest response; in fact, the average daily amount of urine diminished instead of increasing.

The bowels were kept well opened, the abdomen was tapped periodically, and the legs were drained by multiple punctures with aseptic precantions.

Diuretics having failed, a strict salt-free regimen was instituted and persevered with for a month, but no increase in diuresis or diminution of the dropsy resulted.

The ascites was such that tapping was necessary on an average once a fortnight. Altogether the abdomen was tapped twenty-one times, an average of ten pints of fluid being removed at each operation. In addition, a considerable quantity leaked from the abdominal punctures, and much escaped from the punctures in the legs.

In August, 1918, an examination of the blood showed no ures retention, but salt retention was pronounced.

In October Epstein's diet was adopted, and salt was allowed in moderation. For the first three weeks no resalt wo apparent, so salt was again withdrawn. Gradually a change became noticeable in the patient's condition, the amount of urine excreted slowly rising and the dropsy gradually disappearing. The annexed table shows the average urinary excretion for successive three-weekly periods:

\begin{tabular}{|c|c|c|c|c|c|c|c|c|}
\hline \\
\hline \multicolumn{6}{|c|}{ Fivat three weeks Fnstein diet } & & & $27 \mathrm{Qz}$. \\
\hline $\begin{array}{l}\text { Second } \\
\text { Third }\end{array}$ & •• & "• & & $10 \mathrm{~s}$ & lt)... & $\cdots$ & ... & $46 \mathrm{oz}$. \\
\hline $\begin{array}{l}\text { Third } \\
\text { Fourth }\end{array}$ & •• & "• & . & ." & ... & $\cdots$ & $\ldots$ & $51 \cdot \mathrm{dz}$. \\
\hline $\begin{array}{l}\text { Fourth } \\
\text { Fifth }\end{array}$ & " & .• & 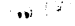 & . & $\ldots$ & ... & $\ldots$ & $67: 08$, \\
\hline & .. &. &.. & ., & $\ldots$ & ... & $\ldots$ & \\
\hline anoth & . & ." & . & . & ... & $\ldots$ & ... & 81 d\%. \\
\hline Feventh & . & . & $\because \gamma$ & .. & ... & $\ldots$ & & \\
\hline ighth & ". &. & & ". & ... & $\cdots$ & $\therefore$ & $113 \mathrm{oz}$. \\
\hline
\end{tabular}


Only three tappings of the abdomen were necessary after commencing the diet, and the oedems of the legs, thighs, scrotum, and penis gradually subsided; the lumbar cushion also disappeared. A marked loss of weight, due no doubt to the elimination of fluid, was later succeeded by a steady gain as nutrition improved. Nothing could be more satisfactory than the way in which the fluid which waterlogged this patient was induced to disperse. His subsequent history is, however, wel worth noting. It is over a twelvemonth since his last tapping. He continues his diet on much the same lines, remains free from ascites and oedema, has put on flesh and looks and feels much better, but his urine is still highly albuminous, and his blood pressure has gradually risen until the systolic pressure is $220 \mathrm{~mm}$. of mercury.

There can be no doubt that the institution of a diet on Epstein's lines was completely successful in restoring this man to a condition of comfort when the ordinary means of treatment combined with salt deprivation had failed. Now, Epstein, as a result of his investigations on renal disease, came to the conclusion that the amount of protein in the blood was very seriously diminished in chronic parenchymatous nephritis, and that this diminution was the direct result of the loss of albumin in the urine. As the result of this there is a diminution in the osmotic pressure of the blood-that is, of the power of the blood to attract fluid from the tissues-a state of affairs which favours the imbibition and retention of fluid by the tissues themselves. Thus he accounts for the oedema and serous effusions met with in chronic parenchymatous nephritis, a form of renal disease in which it is well known that albuminuria is profuse.

Before specifying his diet another point lias to be mentioned: Not only did he find blood protein deficient in these cases, but he also detected a remarkable increase in the lipoid-that is to say, the cholesterin content of the blood, which he attributed to the mobilization of the fatty deposits in the body, and perhaps also to tissue degeneration. Epstein's diet, therefore, is rich in protein and poor in fat to meet these conditions.

EPSTEIN'S DIET.

The daily food value is from 1,280 to 2,500 calories.

Protein from 120 to 240 grams.

Fat (unavoidable) 20 to 40 grams.

Carbohydrates 150 to 300 grams.

The articles used are lean veal lean ham, whites of eggs, oysters, gelatiu, Lima beans, lentils, split peas, green peas,
mushrooms, rice, oatmeal, bananas, skimmed milk, coffee, tea, mushroom

Of fluid, 1,200 to 1,500 c.cm. are allowed, and the amount of salt is in quantity sufficient to make the food palatable.

Fortunately, at the time when this patient was in St. Thomas's Hospital, Drs. MacLean and De Wesselow were already engaged in their investigation on war nephritis which is being carried on there, and I obtained their ready assistance for the investigation of my case.

Two striking facts emerged : tirst, during the period of diuresis the already low protein content of the blood plasma tended rather to diminish than to increase; secondly, the urea content of the blood became angmented. The actual figures were as followis:

\begin{tabular}{|c|c|c|c|c|}
\hline$\therefore:$ & & & $\begin{array}{l}\text { Protein } \\
\text { in Blood } \\
\text { Plasme. }\end{array}$ & Uree in Blood. \\
\hline October 13th, 1918 & $\cdots$ & $\ldots$ & $\begin{array}{c}\text { Per cent. } \\
6.29\end{array}$ & $27 \mathrm{mg}$. per $100 \mathrm{c.cm}$, \\
\hline November 20th, 1918 & $\ldots$ & $\ldots$ & 6.20 & $64 \mathrm{mg}$. per $100 \mathrm{c.cm}$. \\
\hline December 3rd, 1918 & ... & $\ldots$ & 6.00 & $56 \mathrm{mg}$. Der 100 o.cm. \\
\hline January 3rd, 1919 & $\ldots$ & $\cdots$ & - & $81 \mathrm{mg}$. per 100 o.cm, \\
\hline Janụary 22nd, 1919 & $\ldots$ & $\cdots$ & 5.96 & $63 \mathrm{mg}$. per 100 a.cm. \\
\hline
\end{tabular}

These results led Dr. MacLean to infer that; in this instarice at all events, Epsteiri's explanation of the dis. appearance of the dropsical effusions could not apply, and that the diuresis and consequent disappearance of the effuged fluid from the subcutaneous tissues and the serous sacs which resulted from the adoption of the rich protein diet was to be attributed, not to an increased richness of the blood in protein, but to an increase in its urea content, which rose from $27 \mathrm{mg}$. per $100 \mathrm{o.cm}$, at the beginning of the new diet to an average of about $60 \mathrm{mg}$, per $100 \mathrm{ocm}$, Urea is known to be a powerful diuretio, and the adminis. tration of fairly large doses of urea to pationts whö suffer from renal oedema has been found to set up a diuresi similar to that which occurred in the case just narrated.

Whether patients who are the subjects of oedematous renal disease can be injured by the adoption of the high protein diet is a question which calls for serious consideration. The institution of such a diet does not appear to increase in any appreciable degree the amount of albumin which is being lost by the kidneys, and which in itself must bo a serious drain, but, as we have seen, it does undoubtedly increase the amount of urea, and pre. sumably also the other non-protein nitrogenous bodies, in the blood. The administration of urea in large doses occasionally induces headache, but apparently, in healthy persons at all events, has no appreciable effect in raising the blood pressure. My patient, althougl free from oedema and serous effusions and making no complaint of headache or other discomfort, shows a gradually increasing blood pressure, which at the last observation has reached $220 \mathrm{~mm}$. of mercury. It is tempting to associate this rise of pressure with the retention of the non-protein nitrogenous substances in the blood, and it is important to determine whether increased blood pressure is the usual sequel of a rich protein diet in such cases. There is some reason to suspect that it is.

At the same time it is well to bear in mind that patients with large white kidneys who survive the oedematous stage are described as passing into a condition comparable to that induced by contracted granular kidneys-that is to say, a condition in which increasing polyuria is associated with pronounced cardio-vascular changes. It might well be urged, therefore, that the present condition of $\mathbf{m y}$ patient is but the natural result of the evolution of his disease. Whatever be the explanation, the fact remains that the adoption of the high protein diet enables these patients to survive the waterlogged stage and its associated dangers, a survival which experience bas shown was rare before this type of diet was adopted.

As regards diet in acute nephritis we remain mnch where we were. A low protein supply is obviously indicated in the early stage of the disease owing to the presence of urea retention. Should dropsy be present; it is also advisable to restrict or eliminate salt, and not to allow excessive ingestion of fluids. The old warning against beef-tea and meat extracts is justified since they are rich in both salt and nitrogenous derivatives, whilst the idea that toxic products might be eliminated by considerably increasing the fluid intake is not supported by what we know about the mechanism of the oedema. Milk still remains our staple article of food at this stage, not because it is a non-nitrogenous diet, which it assuredly is not, but because it is easily assimilated, slightly diuretic, and by experience found to be least harmful. ' When the acute stage is passed, a rather more liberal protein diet appears to do no harm. The addition of some protein to the carbohýdrates usually allowed at this stage does not appeser to increase the albumin or produce other harmful effects.

As to chronic nephritis of the hydraemic typo, Epstein's diet certainly affords slow and steady relief to the dropsical symptoms, but the ultimate ontcome is still sub judice, whilst in that form of which the granular kidney is the type and urea retention the rule, the established treatment by reducing the protein and extractives is fully corro borated.

\section{THE LIFE-HIS'TORY OF THE FIRST CASE OF MYXOEDEMA TREATED BY THYROID EX'TRACT.}

BI GEORGE R. MURRAY, M.D, D.CI, F.R.C.P. PROFESSOF OP gYETRMATIO MEDTETN IN THE VICPORIA UNTVERSITY, AND PEYBIEIAN TO THE ROYAL INGIRMARX, MANCEESTER : LATELT COLONEL A.M.S. AND CONBULTING PHYSICIAN IN ITALY.

The development of the principles and praetice of enda crinology during the last thirty years has been rapid and progressive. The practice of this branch of medicine has unfortunately not always been based on sound physiological principles, so that glandular extracts have been given indiscriminately in many conditions with disappoint ing results, In the case of some preparations there is little evidence that the hormones they ate supposed to contain are able to exert their normal plyysiological action when given by the mouth. It therefore may be 